\title{
SISTEMA PÚBLICO DE ESCRITURAÇÃO DIGITAL - SPED E OS DESAFIOS DA ÁREA CONTÁBIL JUNTO A TECNOLOGIA
}

\section{ARTIGO ORIGINAL}

VASCONCELOS, Gyselle Aparecida Batista de ${ }^{1}$, ARAGÃO, David dos Santos², ROBERTO, José Carlos Alves ${ }^{3}$, SERRA, Meg Rocha da Cunha ${ }^{4}$, LOPES, Nelânia Ferreira $^{5}$

VASCONCELOS, Gyselle Aparecida Batista de. Et al. Sistema público de escrituração digital - SPED e os desafios da área contábil junto a tecnologia. Revista Científica Multidisciplinar Núcleo do Conhecimento. Ano. 06, Ed. 11, Vol. 15, pp. 75-94. Novembro de 2021. ISSN: 2448-0959, Link de acesso: https://www.nucleodoconhecimento.com.br/contabilidade/area-contabil, DOI: 10.32749/nucleodoconhecimento.com.br/contabilidade/area-contabil

\section{RESUMO}

O presente estudo bibliográfico busca discutir sobre o SPED enquanto solução tecnológica fornecida pela Receita Federal, órgão que oficializa os arquivos digitais gerados pelas escriturações fiscais e contábeis. O SPED é uma forma de cumprimento das obrigações acessórias que substituiu a emissão de livros e de documentos contábeis e fiscais em papel pelo documento eletrônico. Em razão de tantas mudanças impulsionadas pelo surgimento do SPED, surgiu a pergunta problema desta pesquisa: Quais os desafios da área contábil junto à tecnologia relacionada ao SPED? Como objetivo geral, busca-se identificar os efeitos do SPED e verificar os benefícios da solução tecnológica fornecida pela Receita Federal,

\footnotetext{
${ }^{1}$ Graduando do curso de Contabilidade.

${ }^{2}$ Graduando do curso de Contabilidade.

${ }^{3}$ Orientador. Mestrado profissional em Engenharia de produção. Especialização em Gestão em Logística empresarial. Graduação em Administração com Ênfase em Marketing.

${ }^{4}$ Orientadora. Mestra em Engenharia de Processos Industriais pela UFPA, especialista em Controladoria e Auditoria Contábil pelo Ciesa, Graduada em Ciências Contábeis pelo Centro Universitário do Norte. Graduada em Ciências Econômicas pelo Centro Universitário do Norte.

${ }^{5}$ Orientadora. Especialista em Auditoria Contábil, Financeira e Tributária e Graduada em Ciências Contábeis.
}

RC: 102372

Disponível em: https://www.nucleodoconhecimento.com.br/contabilidade/areacontabil 
órgão que oficializa os arquivos digitais, processo que modificou o modo de trabalho dos profissionais da área contábil. A metodologia utilizada neste estudo foi a pesquisa bibliográfica. Como resultados do estudo conclui-se que o processo de incorporação tecnológica e as mudanças ocorridas nos procedimentos contábeis exigiram uma adequação do profissional contábil, considerando que se tornou necessário aos profissionais o aprimoramento e padronização dos processos, com ênfase, também, no compartilhamento de informações contábeis e fiscais e na aceleração do acesso ao cruzamento de dados por meio da auditoria eletrônica. Assim, demonstra-se a nova forma de trabalho dos contadores abrangendo os avanços tecnológicos na contabilidade desde a implementação do SPED. Com este estudo, conclui-se que o SPED veio para melhorar e modernizar o universo das informações contábeis, consequentemente, implicou a atualização dos profissionais contábeis quanto à tecnologia e à legislação pertinente ao SPED, o que fez com que a contabilidade acompanhasse as mudanças tecnológicas que atingiram os profissionais do século XXI.

Palavras-chave: Sistema Público de Escrituração Digital, Contabilidade, Tecnologia, Otimização dos processos.

\section{INTRODUÇÃO}

O presente artigo tem como finalidade apresentar um estudo bibliográfico sobre a importância do Sistema Público de Escrituração Digital - SPED voltado à área contábil, tendo como base em diversos autores e pesquisas, explicando como se dá o processo de incorporação tecnológica por meio do SPED na atividade contábil, contemplando desde a implementação até as mudanças e melhorias nos processos de redução de custos, atentando-se à consolidação de dados na gestão da informação. Com a implementação do SPED, as autoridades fiscais têm acesso à toda informação fiscal, comercial e contábil dos empreendimentos, assim como à entrada de matérias-primas, estoques, saída de produtos e acesso à cada nota fiscal emitida pela empresa (DUARTE, 2011). Diante do exposto, a escolha do problema de pesquisa deu-se mediante ao conhecimento do modo de trabalho utilizado

RC: 102372

Disponível em: https://www.nucleodoconhecimento.com.br/contabilidade/area$\underline{\text { contabil }}$ 
anteriormente pelos contadores, que era uma forma cansativa e que gerava tempo excessivo na formulação das contas contábeis, acumulando milhares de papéis.

O objetivo geral do trabalho propõe-se a demonstrar como o SPED facilita a coleta de dados contábeis, elucidando a nova forma de trabalho dos contadores, baseada em arquivos eletrônicos e amparada em tecnologias que permitem acesso imediato às informações. Nesse sentido, a pergunta problema está ligada ao alvo a ser estudado neste estudo, abrangendo, portanto, a principal função do Sistema Público de Escrituração Digital-SPED, uma inovação tecnológica que substituiu a escrituração física em papel pela escrituração digital, possibilitando a digitalização eletrônica dos livros diário, livro razão, livro balancetes diários, dos balanços e das fichas de lançamento. É necessário construir uma resposta para a pergunta problema, testando, assim, possíveis respostas ou soluções decorrentes de algum fato ou de conhecimentos teóricos (KOCHE, 2011).

Com o avanço tecnológico constante, a contabilidade ganhou um grande aliado, porém, desafios, o que implicou a seguinte pergunta-problema: Quais os desafios da área contábil junto a tecnologia relacionado ao SPED? A metodologia de pesquisa ampara-se em uma pesquisa bibliográfica que analisa 0 interesse nos procedimentos técnicos desenvolvidos na contabilidade, como a coleta de informações e aprimoramentos contábeis por meio do SPED. Quanto à natureza aplicada, a pesquisa caracteriza-se como básica, pois os processos utilizados para o artigo consistem em pesquisa sobre o assunto e análise quanto à importância do SPED para a contabilidade. Quanto aos fins, a pesquisa é descritiva, pois abrange a função do sistema SPED na área contábil, tendo como base as pesquisas já realizadas. $\mathrm{O}$ artigo, quanto aos meios, se deu por meio da pesquisa bibliográfica, reunindo-se, dessa forma, informações que aprimoraram a pesquisa sobre as funções do SPED que unificaram a forma de prestação de informações de interesse fiscal.

Quanto aos objetivos específicos desta pesquisa, visa-se, ao longo do estudo, demonstrar as mudanças tecnológicas que têm afetado os procedimentos contábeis,

RC: 102372

Disponível em: https://www.nucleodoconhecimento.com.br/contabilidade/areacontabil 
exigindo, assim, a adequação do profissional no meio contábil, demonstrando, nessa relação, a conexão que SPED fez com o fisco e com os contribuintes por meio da padronização e compartilhamento das informações contábeis e fiscais. Assim, considerando o problema de pesquisa, apresenta-se a importância do SPED Sistema Público de Escrituração Digital para a contabilidade, no intuito de demonstrar o quanto a tecnologia modificou e inovou o modo de se trabalhar na área contábil, explicando sobre o projeto SPED e seus subprojetos presentes na plataforma, conceituando os módulos mais relevantes para a contabilidade.

\section{FUNDAMENTAÇÃO TEÓRICA}

O presente artigo consiste em uma análise do tema escolhido, tendo como base materiais publicados em revistas, livros, enciclopédias etc. Com apoio nisto, explanar-se-á mais sobre o assunto proposto analisando pesquisas relacionadas ao assunto. Segundo Aragão (2017), as obras a serem utilizadas na proposta e planejamento do processo de pesquisa, bem como os temas relativos ao tema, compõem o referencial teórico.

Conforme destaca Leão (2020):

O Referencial nos apresenta a metodologia e problema nas resoluções com a necessidade norteadora para cada situação, buscando apontamentos técnicos, e propostas metodológicas que abrangem conceitualmente 0 Referencial Teórico afinado do processo de pesquisa e desenvolvimento do profissional.

Para o atual trabalho executado, baseou-se em estudos já realizados por escritores conceituados sobre o tema, proporcionado, com as pesquisas realizadas que debatem e estudam sobre o tema, a explanação do assunto, contudo, o tema foi aprofundado para que obtivesse mais conhecimento para, assim, extrair citações curtas diretas e indiretas por meio das observações e noções do assunto. 


\subsection{CONTABILIDADE NA ERA DA TECNOLOGIA}

Com novas implementações de ferramentas, a analogia à tecnologia é inevitável, o que implica observar que a contabilidade está cada vez mais sendo utilizada com as novas ferramentas da era digital, como observa-se neste presente artigo, pois as análises explanadas apontaram como o SPED é um exemplo de tecnologia implantada na contabilidade. Oliveira (2014), considera que esta facilita a troca de dados entre os escritórios contábeis e as empresas, mitigando os efeitos negativos da falta do setor de informática.

Segundo Teixeira (2015):

O SPED é a nova cara da contabilidade na era da tecnologia, pois tem como objetivo substituir livros e documentos contábeis por documentos eletrônicos. E além disso, visa também, utilizar assinatura de certificado digital. Ressaltando também que o SPED reduzirá fortemente o uso de papel, ou seja, saindo do papel para o formato digital.

Todavia, com as inovações, passa-se a obter uma melhor performance no manuseio das documentações e desenvolvimentos contábeis, o que permite a otimização dos processos, aperfeiçoamentos das gestões, contribuindo, assim, com o alcance de melhor resultado nos negócios.

Para Filho (2010, p. 21):

a modernização de suas unidades, a capacitação de seus servidores, o investimento em infraestrutura, a construção de parcerias nos setores público e privado e a utilização da internet como um ambiente para a prestação de serviços e informações são exemplos claros dessa postura. O sítio da Receita Federal, especificamente, além de criar facilidades de atendimento aos contribuintes, têm incentivado a inclusão digital e promovido a redução de custos de toda ordem, tanto para o Estado como para o cidadão.

A contabilidade na era da tecnologia tem ganhado alguns aliados que otimizam os processos contábeis, o que fez com que o contador tenha uma visão ampla sobre o que acontece no dia a dia da empresa. A facilidade no envio de contas obrigatórias diminuiu de maneira considerável e efetiva todos os erros e fraudes na área. Implementar o SPED nas empresas é um grande exemplo de inovação nas áreas

RC: 102372

Disponível em: https://www.nucleodoconhecimento.com.br/contabilidade/areacontabil 
contábeis, pois demonstrou-se que os papéis impressos, processos manuais, estão cada vez mais sendo excluídos do dia a dia do contador, pois a era digital adentrou na área contábil e, com isso, em muitos escritórios. O processo pode ser observado pelo amplo uso do mesmo, o que torna esta tecnologia bem aceita.

\subsection{SISTEMA PÚBLICO DE ESCRITURAÇÃO DIGITAL- SPED}

As inovações tecnológicas e o mundo cada vez mais influenciado por tais mudanças exigem que profissionais se adequem às evoluções técnicas. $O$ contador não deixa de ser afetado pela inovação. Com isso, o Governo Federal criou o Sistema Público de Escrituração Digital para recebimento de informações fiscais e contábeis das empresas, o que, também, em virtude dos benefícios, acabou facilitando a integração entre as três esferas governamentais fiscalizadoras: federal, municipal e estadual. Para Oliveira (2019), atualmente, o fisco deve estar ciente de tudo o que acontece em relação aos aspectos fiscais nas empresas, desde compras de mercadorias até as prestações de serviços, inventário, área de produção, cartão de crédito e folha de pagamento.

Diante disso Nascimento (2013) destaca que:

No Brasil, hoje, não é nenhuma novidade quando falamos sobre carga tributária, devido a grandes eventos e falas acerca do tema. Certamente, com o início do SPED e a importância para as empresas e contribuintes essa realidade do uso do sistema beneficia sem dúvida a forma de como as informações atendam às necessidades do mundo virtual, as empresas com sistema moderno.

O projeto SPED facilita o manuseio de alguns aspectos, como a forma de cumprimento das obrigações essenciais feitas pelos contribuintes, contando com a substituição de livros e documentos contábeis e fiscais que eram feitos em papéis pela estratégia agora permitida: a formulação por meio eletrônico, sendo validado por meio da certificação digital. Uma das contribuições do SPED é poder integrar os fiscos por meio de compartilhamentos de informações contábeis, facilitando, assim, o controle de processos, bem como faz com que haja uma maior rapidez no que toca ao acesso às informações, em conjunto com uma fiscalização mais efetiva das

RC: 102372

Disponível em: https://www.nucleodoconhecimento.com.br/contabilidade/area$\underline{\text { contabil }}$ 
operações, pois conta-se com cruzamento de dados, facilitando que processos ilícitos tributários sejam identificados com mais rapidez e eficácia. O SPED é composto por subprojetos:

- Substituição de livros, como a razão e diário, para a uma plataforma digital, Escrituração Contábil Digital- ECD;

- Registros fiscais que substituem livros fiscais e registros de entrada/saída, Escrituração Fiscal Digital- EFD;

- Emissão de documentos fiscais substituídos por documentos eletrônicos, Nota Fiscal Eletrônica- NF-e;

- Substituição de documentos fiscais, como da Nota Fiscal de Serviço de Transporte Ferroviários de Cargas, entre outros meios de transporte idealizado, pelo Conhecimento de Transporte eletrônico- CT-e;

- Eliminação na redundância de informações da escrituração contábil, E-Lalur;

- Disponibiliza por meio magnético informações acerca das demonstrações contábeis e econômico-financeiras, Central de Balanços.

Portanto o SPED não deve ser visto pelos contadores e empresários como uma barreira, mas sim como uma ferramenta tecnológica que facilita a implementação de uma nova gestão tributária, tendo como avanço a melhoria dos processos digitais e operacionais dos contribuintes, pois o sistema evita erros e riscos inerentes ao mercado.

\subsubsection{NOTA FISCAL ELETRÔNICA- NF-E}

NF-e é um documento que serve para registrar a venda de produtos e apresenta dados sobre a prestação de serviços para que o estabelecimento possa continuar realizando seus serviços conforme determina a lei. As empresas são obrigadas a emitirem a nota fiscal. Guerra (2017), entende que a NF-e dispõe de informações gerencias sobre a empresa, código interno, unidade de medida, descrição do produto. Estas são algumas das medidas disponíveis na nota fiscal eletrônica que compõem a escrituração digital.

RC: 102372

Disponível em: https://www.nucleodoconhecimento.com.br/contabilidade/areacontabil 
Conforme Duarte (2016):

Com a apresentação da grande e notável expansão, empresas buscaram soluções que atendessem demandas e com o processo de implantação passaram por processo e meses com dificuldades devido à NF-e ser um fenômeno recente. Mas em resposta com o tempo os benefícios foram assinalados com a redução de custos com armazenamento de documentos antigos, que permitirá em prazos retornos de investimentos.

O objetivo de maior importância do NF-e é evitar que ocorram evasões fiscais, como a sonegação de impostos por parte dos empresários. Então, todas as vezes em que houver movimentação de um produto para venda, transferência, devolução entre filiais e consumidores finais, a emissão da NF-e deverá ser feita A nota fiscal eletrônica é armazenada eletronicamente, elaborada de modo digital, com intuito de relatar as prestações e operações. A validade do NF-e é apenas jurídica, em razão do formato da assinatura digital do emitente. Todavia, a autorização do uso é determinada pela administração tributária da unidade federal do contribuinte, sendo necessário ser autorizada antes que seja instituído o fator gerador da nota (FILHO, 2010). Enfatiza-se que nota fiscal eletrônica é um documento que o consumidor pode exigir, pois é de seu direito, para que trocas, devoluções e até mesmo parte do dinheiro possam ser exigidos de volta, desde que apresentada a certificação da nota fiscal do produto que foi identificado com falha.

\subsubsection{ESCRITURAÇÃO DIGITAL CONTÁBIL - ECD}

O SPED CONTÁBIL- ECD foi instituído por uma instrução normativa da receita federal. É uma forma de substituir os envios de balancetes e do livro diário para uma forma eletrônica, fazendo, assim, com que trabalhos manuais, como documentos em papéis, tornem-se cada vez mais desnecessários na área contábil. Conforme Teixeira (2015), destaca-se que SPED contábil, conhecido como Escrituração Contábil Digital-ECD, substituiu a escrituração em papel, tendo-se a escrituração contábil digital- ECD.

Segundo Henrique (2016):

RC: 102372

Disponível em: https://www.nucleodoconhecimento.com.br/contabilidade/areacontabil 
A ECD realmente foi desenvolvida como uma das grandes inovações do sistema SPED, e um dos efeitos dessa novidade foi que, aos obrigados determinados pela legislação, não e autorizado imprimir os Livros Diários para o mesmo período, ou seja, o livro contábil válido será somente o digital transmitido, recebido e autenticado pelo sistema SPED.

O Sistema Público de Escrituração Digital é uma solução digital que oficializou os arquivos digitais das escriturações fiscais e contábil dos sistemas empresariais dentro de um formato padronizado. Sendo assim, é o sistema atual utilizado na contabilidade das empresas desde 28 de maio de 2009, conforme o ato declaratório executivo COFINS n20. Dispõe sobre tabelas de códigos e regras relacionados à validação, aplicáveis à Escrituração Contábil Digital. ECD, assim como os demais módulos do SPED, surge para eliminar os processos manuais em papel, tornando tudo digital, rápido e de fácil acesso, tanto para o fisco quanto para os contadores e contribuintes. Portanto, a rotina é modificada, sendo que, ao invés de apresentar os livros padrões contábeis para registro na junta comercial, o mesmo será validado por meio eletrônico.

\subsubsection{ESCRITURAÇÃO FISCAL DIGITAL- EFD}

EFD é mais um dos avanços que compõem o SPED. É de suma importância para a contabilidade, pois os dados da contabilidade todos migraram do modo manual para o digital, reduzindo os custos com impressão dos livros fiscais, diminuindo, também, o espaço de armazenamento, proporcionando, aos órgãos fiscalizadores, um controle mais apurado e preciso quanto à movimentação realizada pelos contribuintes. Oliveira (2020), aponta que a escrituração fiscal no século XXI não está ligada a procedimentos repetitivos e operacionais, sendo uma medida de análise de inteligência e tecnologia fiscal.

Para Oliveira (2019):

O SPED é o momento de grande transformação para a sociedade e para o mundo empresarial, pois é sem sombra de dúvidas um dos maiores desafios e padrões, padrões que facilitam a gestão por possuir novas tecnologias que possibilitam gerar, distribuir e transmitir a informação ao cliente, o

RC: 102372

Disponível em: https://www.nucleodoconhecimento.com.br/contabilidade/areacontabil 
transportador, o recebimento do arquivo do fornecedor e a permanência do documento disponível para mais de cinco anos.

Pode-se citar alguns dos livros que poderão ser substituídos pelo sistema EFD, como registro de entradas, registros de saída, registro de inventário, registo de apuração do IPI e registro de apuração do ICMS. De acordo com Filho (2010), a empresa deve elaborar um documento digital a partir da base de dados e conforme o layout instituído em Ato pela Comissão Técnica Permanente do ICMS (Cotepe), apresentando nestes documentos fiscais, e outros dados relevantes ao fisco federal e estadual, relativos à um determinado período de apuração dos impostos ICMS e IPI. Desta forma, esses documentos deverão ser validados pelo Programa Validador e Assinador (PVA) promovido pelo SPED.

Contudo, os contabilistas devem estar atentos às mudanças tecnológicas e aprimoramentos de fiscalização para não serem pegos de surpresa pelo governo ao exigir tais substituições feitas corretamente por meio do EFD destinado aos empresários, contadores e contribuintes.

\subsubsection{CONHECIMENTO DE TRANSPORTE ELETRÔNICO - CT-E}

O CT-e é um documento fiscal de emissão obrigatória e de grande importância para as transportadoras que possuem uma ligação com transporte rodoviário e de cargas e de importância para o fisco. Não o emitir ou deixar de preenchê-lo corretamente pode ocasionar multas desnecessárias ou até mesmo as mercadorias podem ser apreendidas pelo órgão fiscalizador. O Transporte Eletrônico-CT-e deverá ser feito tendo como base o documento fiscal eletrônico, destinado, portanto, aos meios de transporte rodoviário e, em um futuro breve, abarcará vários modos de transporte (DUARTE, 2016).

Segundo Teixeira (2015):

O CT-e - Conhecimento de Transporte eletrônico, sendo um novo modelo de documento fiscal, totalmente digital que visa documentar a prestação de serviços, emissão, e armazenamento eletrônico. A sua validade é jurídica

RC: 102372

Disponível em: https://www.nucleodoconhecimento.com.br/contabilidade/areacontabil 
sendo dessa forma garantida pela assinatura digital de quem está emitindo e a autorização de uso fornecida pela administração tributária.

Não podemos deixar de citar que o CT-e é um documento de existência apenas digital, sendo um novo modelo de documento fiscal eletrônico. O mesmo surge para substituir alguns documentos como: Conhecimento de Transporte Rodoviário de Cargas [CTRC], Modelo 8, Conhecimento de Transporte Aéreo, Modelo 10, Conhecimento de Transporte Ferroviário de Cargas, Modelo 11, Nota Fiscal de Serviço de Transporte, Modelo 7, dentre outros.

CT-e, exclusivamente conceituado como um documento de existência digital, é emitido e armazenado eletronicamente, com o objetivo de documentar a prestação dos serviços feitos por meio de transportes. A assinatura digital concerne à validade jurídica do emitente. Por outro lado, a autorização é fornecida por meio da administração tributária de domicílio do contribuinte (GUERRA, 2017).

Portanto, o objetivo do CT-e é ser um sistema que fiscalize a prestação de serviço de transporte de carga quanto aéreo, rodoviário, aquaviário, dutoviário e ferroviário. Com a emissão correta do CT-e, as transportadoras estão certificando ao fisco sobre a operação de transporte que estão realizando.

\subsubsection{EMPRESAS ENQUADRADAS NA ENTREGA DO SPED CONTÁBIL}

Esta obrigação é exigida pelo governo para as empresas que estão ligadas ao regime de tributação do lucro presumido e real. Todavia, as empresas que estão no simples nacional não precisam integrar o SPED contábil, como aponta o Art. 3 da instrução normativa RFB № 1.420/2015, relacionado aos fatos contábeis, de modo que foram obrigados a adotar O ECD a partir de 1 de janeiro de 2016. As autoridades fiscais, depois de bastante trabalho, desenvolveram o SPED que, em muitos momentos, atuaram em conjunto com as empresas privadas que estavam envolvidas no projeto (DUARTE, 2016).

RC: 102372

Disponível em: https://www.nucleodoconhecimento.com.br/contabilidade/areacontabil 
Conforme afirma Guerra (2017):

A aplicação obrigatória do SPED Contábil aplica-se às pessoas jurídicas tributadas com base no lucro presumido, a título de lucros, sem incidência do imposto sobre a renda retido na fonte, parcelas dos lucros superiores ao valor da base de cálculo do imposto. Destacando que tal obrigatoriedade foi até 2015, assim surgindo dúvidas, pois não houve um esclarecimento em relação sobre a definição de impostos para fins de cálculo.

Para a formulação do ECD, primeiramente, a escrituração é realizada, gerando, assim, um arquivo que o contador deverá assinar. Depois o mesmo é enviado para o cliente. É importante enfatizar que tudo é realizado de modo digital por meio do SPED. Portanto, o SPED CONTÁBIL veio para facilitar o cotidiano contábil. Observou-se que a facilidade para entrega do livro diário e balancete fez com que as empresas não deixassem de enviar aos seus clientes esses livros de suma importância para o parâmetro do empreendimento. O SPED é uma das obrigações que os empresários devem estar atentos, já que mudanças ocorrem no sistema, sendo importante, também, porque unifica as obrigações como: reduzir custos ao dispensar a emissão e aos armazenamentos dos documentos em papel, uniformizar as informações que os contribuintes prestam às unidades federadas e rapidez no acesso às informações, facilitando, assim, o compliance e a gestão.

Além disso, reduz os custos administrativos, possibilita o cruzamento de dados contábeis e fiscais e disponibiliza cópias autênticas e válidas da escrituração. Em uma empresa, deve haver sistema de gestão que adote controles internos e de estoque, de modo que seus funcionários tenham a capacidade de emitir notas fiscais eletrônicas (OLIVEIRA, 2014).

Segundo Nascimento (2013):

Com essa visão, antecipadamente chamo a atenção do empresário que, se antes o ambiente governamental já era a extensão da sua empresa, agora com o ambiente virtual requerido pelas novas exigências, essa extensão passa a ser tipificada. Cada vez mais os líderes das empresas precisam acreditar que o mundo hoje é colaborativo entre todos e suas informações não podem ser mais guardadas em "cofres", senão em gavetas e armários.

RC: 102372

Disponível em: https://www.nucleodoconhecimento.com.br/contabilidade/area$\underline{\text { contabil }}$ 


\subsection{VANTAGENS DO SPED PARA FISCO, EMPRESAS E A SOCIEDADE}

Entre os principais objetivos do SPED, destacam-se três fatores como sendo os mais importantes, são eles: favorecer a integração dos fiscos; tornar mais eficientes e uniformes as obrigações acessórias aos contribuintes; e tornar mais rápida e eficiente a identificação de ilícitos tributários (DUARTE, 2012). Além da atualização e melhora dos processos por meio dos sistemas digitais, o SPED apresenta outros objetivos que facilitam o controle por parte da Receita Federal e que exercerão impacto positivo no sistema contábil brasileiro, como a redução com os custos de emissão e armazenamento de documentos em papel (RECEITA FEDERAL, 2021). Entretanto, a implementação da ferramenta poderia não eliminar totalmente o uso de papel, uma vez que cabe aos contribuintes manterem os livros impressos ou em arquivos digitais.

Com o SPED, visa-se, ainda, fomentar uma padronização das informações que o contribuinte oferece às diversas unidades federadas. Tal medida facilita não apenas o processo de declaração realizado pelo contribuinte, que passará a seguir um único modelo, padronizado, para a sua declaração, mas também facilita o cruzamento das informações e dados contábeis e fiscais, mitigando qualquer tipo de erro ou tentativa de fraude. Segundo a Secretaria da Receita Federal do Brasil (2013), o SPED tornase realmente eficiente. Nesse sentido, foram estabelecidas quais sociedades empresariais deveriam fazer utilização do mesmo, assim como foi determinado o prazo máximo para a adequação de tais sociedades. O SPED proporciona diversas vantagens para todas as partes, seja ao fisco, às empresas e até mesmo à sociedade.

As principais vantagens do SPED para o fisco, para a empresa e para a sociedade, segundo a Receita Federal (acervo digital), são: 
Quadro 1 - Vantagens do SPED - Fisco, Empresa e Sociedade

\begin{tabular}{|c|c|c|}
\hline Fisco & Empresas & Sociedade \\
\hline $\begin{array}{l}\text { Maior integração entre os } \\
\text { fiscos e melhor controle } \\
\text { administrativo; }\end{array}$ & $\begin{array}{l}\text { Possibilita a melhoria e o } \\
\text { aperfeiçoamento dos } \\
\text { processos internos de } \\
\text { faturamento e logística } \\
\text { operacional; }\end{array}$ & $\begin{array}{l}\text { Preservação do meio } \\
\text { ambiente com redução } \\
\text { de consumo de papel; }\end{array}$ \\
\hline $\begin{array}{l}\text { Menor envolvimento } \\
\text { involuntário em práticas } \\
\text { fraudulentas; }\end{array}$ & $\begin{array}{l}\text { Descarta erros de } \\
\text { escrituração no registro de } \\
\text { NF-e e de entradas e } \\
\text { saídas de mercadorias; }\end{array}$ & $\begin{array}{l}\text { Redução do Custo } \\
\text { Brasil; }\end{array}$ \\
\hline $\begin{array}{l}\text { Melhoria na qualidade da } \\
\text { informação com o } \\
\text { consequente } \\
\text { aperfeiçoamento dos } \\
\text { processos de controle } \\
\text { fiscal; }\end{array}$ & $\begin{array}{l}\text { Redução de custo com a } \\
\text { racionalização das } \\
\text { simplificação } \\
\text { obrigações acessórias; }\end{array}$ & $\begin{array}{l}\text { Incentivo ao uso de } \\
\text { relacionamentos } \\
\text { eletrônicos entre } \\
\text { empresas (B2B); }\end{array}$ \\
\hline $\begin{array}{ll}\text { Aperfeiçoamento do } \\
\text { combate à sonegação. }\end{array}$ & $\begin{array}{l}\text { Minimiza os custos } \\
\text { administrativos com a } \\
\text { dispensa de emissão e } \\
\text { armazenamento } \\
\text { documentos em papel. }\end{array}$ & $\begin{array}{l}\text { Utilização de padrões } \\
\text { abertos (Web } \\
\text { Services, Internet). }\end{array}$ \\
\hline
\end{tabular}

Fonte: Secretaria da Receita Federal do Brasil (acervo digital) 2021

\subsection{DESAFIO DO SPED NA PROFISSÃO CONTÁBIL}

Segundo Nascimento (2013), os escritórios e os profissionais têm enfrentado um dilema, pois nem todos estão preparados para darem o suporte necessário às suas empresas frente a essa realidade do SPED.

RC: 102372

Disponível em: https://www.nucleodoconhecimento.com.br/contabilidade/areacontabil 
O SPED foi criado para gerar um impacto tecnológico na área contábil, diminuindo, também, um dos problemas do Brasil, que é a burocracia, sendo um processo que tem envolvido as empresas, receitas federais e o ambiente contábil. Para Oliveira (2020), há uma crescente na capacitação dos profissionais que priorizam a busca contínua pelo conhecimento, com vistas à melhora do desempenho profissional.

Segundo Duarte (2011):

A responsabilidade do contador para sociedade e para as empresas torna-se maior, fazendo com que assim o trabalho manual e operacional seja sobreposto muitas vezes pelo intelecto. A empresa não tem como funcionar sem o planejamento tributário, contabilidade gerencial e auditoria, tarefas típicas do contador.

O Sistema Público de Escrituração Digital facilita o envio de informações, padronizando os sistemas para que os conteúdos sejam simplificados. $\mathrm{O}$ arquivo digital gerado no SPED é validado e assinado no próprio sistema. Para o mundo contábil, o sistema SPED surgiu para auxiliar na mudança de hábitos e evolução dos mesmos, mudando o papel para a digitalização, reduzindo custo, reduzindo tempo, burocracia, bem como evita erros. Com isso, a contabilidade se integra na era digital, surgindo, assim, uma nova forma de trabalho para os contadores. Tal evolução atingiu tanto os contadores quanto as empresas, em todos os segmentos, e isso despertou as verdadeiras mudanças na forma que operam e comercializam.

Ruschel et al. (2011), por sua vez, constataram que, no âmbito da contabilidade, o SPED exerce maior impacto na fidedignidade e qualidade dos dados. Eles esperam que essa mudança promova agilidade e clareza aos dados, de modo que o contador não mais exercerá o papel de digitador, mas sim o de assessor às empresas, trabalhando com dados verídicos e confiáveis. Com o objetivo de promover a transição dos controles fiscais e contábeis para o padrão digital, a implantação do SPED tem obrigado as empresas, independentemente do tamanho, a fazerem grandes adaptações em suas estruturas internas (NASCIMENTO, 2013).

RC: 102372

Disponível em: https://www.nucleodoconhecimento.com.br/contabilidade/areacontabil 


\subsection{DESAFIOS DAS EMPRESAS ENQUADRADAS NO SPED}

Para as empresas, a implementação do SPED Contábil, além de ser obrigatória, é válido citar, também, a sua importância para a gestão empresarial de sucesso, fazendo com que as obrigações sejam transmitidas corretamente. Todavia, o empresário tem que saber empregar a contabilidade digital, não dependendo apenas do contador. Ao mesmo tempo, tem-se o desafio de aliá-la à tecnologia, encontrando, assim, a melhor solução fiscal, devendo esta se adequar ao empreendimento. Os empresários devem estar conscientes de que a tecnologia é um poder aliado ao fisco que potencializa o poder de análise que foca nas grandes, pequenas e microempresas, saindo do tempo em que o fisco apenas analisava as grandes empresas, identificando os tempos modernos em que nos encontramos, em que fiscalização eletrônica abrange todas e quaisquer empresas (OLIVEIRA, 2014).

No entendimento de Schein (2009), cultura organizacional é o conjunto de pressupostos básicos que um grupo inventou, descobriu ou desenvolveu ao aprender como lidar com os problemas de adaptação externa e integração interna e que funcionaram bem o suficiente para serem considerados válidos e ensinados a novos membros como a forma correta de perceber, pensar e sentir em relação a esses problemas. Para Chiavenato (apud BARNARD, 2006), a organização é um sistema de atividades conscientemente coordenadas que envolvem duas ou mais pessoas, sendo esta cooperação essencial para sua existência. Conforme os autores, uma organização apenas existe quando há pessoas capazes de se comunicar, que estão dispostas a contribuir com a ação e que cumprem a tarefa com um propósito em comum.

Além das dificuldades tecnológicas inerentes aos programas, softwares e sistemas que interligam as empresas ao SPED, a falta de profissionais qualificados no momento de mudanças dentro das empresas gera a necessidade de capacitar os colaboradores para lidarem com o SPED. Torna-se necessário fazer investimentos na realização de treinamentos e refletir sobre o avanço tecnológico que afeta os envolvidos no processo.

RC: 102372

Disponível em: https://www.nucleodoconhecimento.com.br/contabilidade/areacontabil 


\section{MATERIAIS E MÉTODOS}

A metodologia se faz necessária já que a mesma descreve uma abordagem para chegar ao objetivo final. Descreve-se, em detalhes, cada etapa da pesquisa, traçando uma estratégia geral. Todavia, cada metodologia seguirá uma abordagem diferente, adequando-se ao problema a ser enfrentado no trabalho de observação.

Portanto, neste trabalho, foram abrangidas diversas ferramentas que captam o conhecimento, com intuito de aprimorar os métodos de pesquisa sobre o tema, analisando o tema e o problema que o abrange para, assim, ressignificar a sua importância para a área contábil.

\subsection{PROCEDIMENTOS METODOLÓGICOS}

Metodologia faz parte do estudo quando o autor indica métodos que serão essenciais para a formalização da pesquisa. Usualmente, nas pesquisas, há ações, etapas, técnicas para sua realização (SILVA; PORTO, 2016). Forma um conjunto que permite as tomadas de decisões relacionadas às técnicas a serem usadas para o desenvolvimento do trabalho científico. Esta pesquisa foi desenvolvida por meio do interesse no procedimento técnico que foi incrementado na contabilidade, coletandose, nesse processo, todas as informações e aprimoramentos contábeis por meio do SPED, demonstrando como a tecnologia ajudou os contadores no momento dos lançamentos.

\subsubsection{QUANTO À NATUREZA}

Segundo Menezes (2019), quanto à natureza, o pesquisador tem sua grande importância na interpretação do assunto a ser abordado, principalmente se a pesquisa for qualitativa.

O homem não se opõe a fazer uso de sua inteligência e perspectivas para que haja melhoras no esclarecimento daquilo que lhe faz acentuar sua curiosidade e sentidos (LIMA; PEREIRA, 2018).

RC: 102372

Disponível em: https://www.nucleodoconhecimento.com.br/contabilidade/area$\underline{\text { contabil }}$ 
A natureza aplicada à pesquisa científica foi básica, já que os processos a serem utilizados para o projeto foram a pesquisa sobre 0 assunto e a análise da importância do mesmo para a contabilidade. A pesquisa partiu de uma abordagem bibliográfica, pois o trabalho foi baseado em pesquisas, artigos, livros e revistas científicas, sendo esses materiais utilizados como citações que aprimoraram a pesquisa.

\subsubsection{QUANTO AOS FINS}

Segundo Aragão e Neta (2017), para elaboração do projeto de pesquisa, o método é básico, pois é capaz de orientar a parte do corpo na escolha do material para a investigação.

A pesquisa descritiva apresenta o que é abordado no texto usando aspectos como: descrição, interpretação de assuntos atuais e análise de seu funcionamento no presente (IRMAÑA- ENCINAS; SANTANA, 2019).

Quanto aos fins, a pesquisa será descritiva para que fosse possível descrever sobre o tema, caracterizá-lo com base em pesquisas já realizadas, abordar conhecimento prévio sobre o assunto e reunir informações baseadas em documentos já adquiridos por meio de pesquisas realizadas sobre o assunto explanado, debatendo a partir da lógica do presente.

\subsubsection{QUANTO AOS MEIOS}

Pesquisa quanto aos meios é o ajuste da área a ser estudada, isto é, quando são iniciados os estudos bibliográficos, estabelecendo-se, nesse momento, os termos e expressões a serem usados na parte conceitual do trabalho (BARROS; ROSA; RIBEIRO, 2017). Segundo Vergara (2016), a pesquisa bibliográfica é acessível a todos, pois é um estudo desenvolvido por meio de revistas, jornais, livros, sendo assim, tem-se uma base que é compreensível ao leitor.

RC: 102372

Disponível em: https://www.nucleodoconhecimento.com.br/contabilidade/areacontabil 
O projeto, quanto aos meios, foi realizado por meio de pesquisa bibliográfica, que é, geralmente, um dos passos principais de qualquer pesquisa, pois procura explicar o assunto abordado a partir de referências já publicadas, com o objetivo de reunir informações para o aprimoramento de uma pesquisa e explanação da importância do tema.

\section{CONSIDERAÇÕES FINAIS}

A pesquisa teve como objetivo geral constatar as mudanças significativas ocorridas nos procedimentos contábeis com a alteração da escrituração manual para a total digitalização dos dados contábeis, abordando a importância do SPED para a área contábil. Foi constatado que o objetivo geral foi atendido, porque o trabalho conseguiu demonstrar, de forma bibliográfica, que o SPED implantado no mundo contábil inseriu mudanças significativas no modo de contabilizar, apontando a facilidade no novo modelo de lançamento contábeis por meio digital. Ao retomar a pergunta problema estabelecida: Quais os desafios da área contábil junto a tecnologia relacionado ao SPED? relatou-se que o processo de incorporação tecnológico e as mudanças ocorridas nos procedimentos contábeis exigiram uma adequação do profissional contábil à nova realidade, considerando que se tornou necessário o aprimoramento da padronização dos processos e compartilhamento de informações contábeis e fiscais.

Buscou-se o perfeito entendimento da aceleração do acesso ao cruzamento de dados por meio da auditoria eletrônica. Assim, demonstrou-se a nova forma de trabalho dos contadores, abrangendo os avanços tecnológicos que afetaram contabilidade desde a implementação do SPED, que surgiu para melhorar e modernizar o universo das informações contábeis. Tornou-se necessária, consequentemente, a atualização dos profissionais contábeis quanto à tecnologia e à legislação pertinente ao SPED. Isto fez com que a contabilidade acompanhasse as mudanças tecnológicas e profissionais do século XXI. A principal função do SPED, que inicialmente foi formulado para minimizar o trabalho e facilitar a coleta de dados contábeis, porém, ao decorrer do artigo, como apontaram as respostas à pergunta

RC: 102372

Disponível em: https://www.nucleodoconhecimento.com.br/contabilidade/areacontabil 
problema, teve como principal função do Sistema Público de Escrituração Digital SPED é facilitar o cumprimento das obrigações fiscais, resultando, assim, no aceleramento do processo de crescimento econômico.

Unificou-se a forma de prestação e informações de interesses fiscais, dando ênfase na modificação da forma de cumprimento das obrigações acessórias, substituindo a emissão de livros e de documentos contábeis e fiscais em papel por documento eletrônico. Ao retomar os objetivos específicos estabelecidos inicialmente, possibilitou-se demonstrar a importância do Sistema SPED aplicado à contabilidade. Explanou-se os subprojetos presentes no SPED e argumentou-se sobre o novo modo de contabilização na era digital, concentrando-se a importância do mesmo para o fisco e os contribuintes. O primeiro objetivo específico foi respondido, haja vista que foi elucidado no trabalho o processo de incorporação tecnológica por meio do SPED na atividade contábil. Dessa forma, o segundo objetivo específico foi atendido, pois analisou-se a evolução tecnológica, constatando-se que o SPED aprimorou os procedimentos contábeis, atendendo, assim, desde o meio contábil até o fiscal.

terceiro objetivo específico demonstrou, considerando o cenário analisado, a importância do SPED na contabilidade, desde a implementação dos subprojetos nos processos e redução de custos até a forma de fazer lançamentos contábeis. Durante a pesquisa, constatou-se que o SPED trata-se uma solução tecnológica a qual o profissional contábil teve que se adequar, pois o Sistema Público de Escrituração Digital é um dos sistemas mais utilizados pelos contadores, principalmente na área empresarial, sem deixar de abordar a importância do sistema que facilitou o envio das contas contábeis e implementou o certificado digital na contabilidade para as empresas.

\section{REFERÊNCIAS}

ARAGÃO, J. W. M. de.; NETA, M. A. H. M. Metodologia Científica. Salvador: UFBA, 2017.

RC: 102372

Disponível em: https://www.nucleodoconhecimento.com.br/contabilidade/areacontabil 
BARROS, S.; ROSA, F.; RIBEIRO, E. M. Princípios e técnicas para elaboração de textos acadêmicos. $1^{\text {a }}$ ed. Salvador: UFBA, 2017.

CHIAVENATO, I. Administração de Recursos Humanos. 6ª ed. São Paulo: Editora Atlas, 2006.

DUARTE, R. D. Maioria dos dados enviados ao Fisco apresenta divergências. Disponível em: http://www.robertodiasduarte.com.br/maioriados-dados-enviados-aofisco-apresenta-divergencias/. Acesso em: 23 ago. 2012.

DUARTE, R. D. Big Brother Fiscal - III - Manual de sobrevivência do empreendedor no mundo pós - SPED. Belo Horizonte: ideias@work, 2016.

DUARTE, R. D. Big Brother Fiscal - IV - Manual de sobrevivência do empreendedor no mundo pós- SPED. Belo Horizonte: ideias@work, 2011.

FAZENDA, Secretaria da. Guia prático de Escrituração Fiscal Digital. Disponível em: Acesso em 23 out. 2021.

FILHO, A. Da escrituração manual ao SPED: a relação do Fisco com as empresas. Porto Alegre: Conselho Regional de Contabilidade do Rio Grande do Sul, 2010.

GUERRA, F. Descomplicando o SPED: aspectos operacionais do Sistema Público de Escrituração Digital. Fortaleza: Fortes, 2017.

HENRIQUE, M. de. A. Livros contábeis e escrituração contábil no atual cenário tributário. São Paulo: Trevisan Editora, 2016.

IRMAÑA-ENCINAS, J.; SANTANA, O. A. O trabalho científico na metodologia científica. Brasília: Universidade de Brasília, Departamento de Engenharia Florestal, 2019.

KÖCHE, J. C. Fundamentos de metodologia científica: teoria da ciência e iniciação à pesquisa. Petrópolis: Vozes, 2011.

RC: 102372

Disponível em: https://www.nucleodoconhecimento.com.br/contabilidade/areacontabil 
LEÃO, R. de. S. O Ensino de Filosofia segundo o referencial curricular da rede de ensino do estado de Alagoas. 2020. 74f. Dissertação (Mestrado em Filosofia) Universidade Federal de Pernambuco, Recife, PE, 2020.

LIMA, P. G.; PEREIRA, M. C. (Orgs). Pesquisa científica em ciências humanas: uma introdução aos fundamentos e eixos procedimentais. Uberlândia: Navegando Publicações, 2018.

MENEZES, A. H. N. et al. Metodologia científica: teoria e aplicação na educação a distância. Petrolina, PE: Universidade Federal do Vale do Rio São Francisco, 2019.

NASCIMENTO, G. C. SPED Sistema Público de Escrituração Digital sem armadilhas. São Paulo: Trevisan Editora, 2013.

OLIVEIRA, A. M. de. Escrituração Fiscal no Brasil: conhecer, analisar e executar. São Paulo: Senac, 2020.

OLIVEIRA, A. S. de. Estoque do SPED Fiscal: manual do escritório contábildesvendando os mistérios dos blocos K e F. São Paulo: Labrador, 2019.

OLIVEIRA, A. S. de. SPED nas pequenas empresas: como atender as exigências do fisco na era digital. $1^{\text {a }}$ ed. São Paulo: Trevisan Editora, 2014.

RUSCHEL, M. E.; FREZZA, R.; UTZIG, M. J. S. O impacto do SPED na contabilidade, desafios e perspectivas do profissional contábil. Revista Catarinense da Ciência Contábil, v. 10, n. 29, p. 09-26, 2011.

RECEITA FEDERAL. Sped. Sistema público de escrituração digital. Disponível em: http://www1.receita.fazenda.gov.br/Sped/. Acesso em: 23 out 2021.

SILVA, C. N. N. da.; PORTO, M. D. Metodologia científica descomplicada: prática científica para iniciantes. Brasília: IFB, 2016.

SCHEIN, E. H. Cultura organizacional e liderança. São Paulo, Atlas 2009. 
TEIXEIRA, T. Curso de direito e processo eletrônico: doutrina, jurisprudência e prática. $3^{a}$ ed. São Paulo: Saraiva, 2015.

VERGARA, S. C. Projetos e relatórios de pesquisa em administração. 16 ed. São Paulo: Atlas, 2016.

Enviado: Outubro, 2021.

Aprovado: Novembro, 2021. 